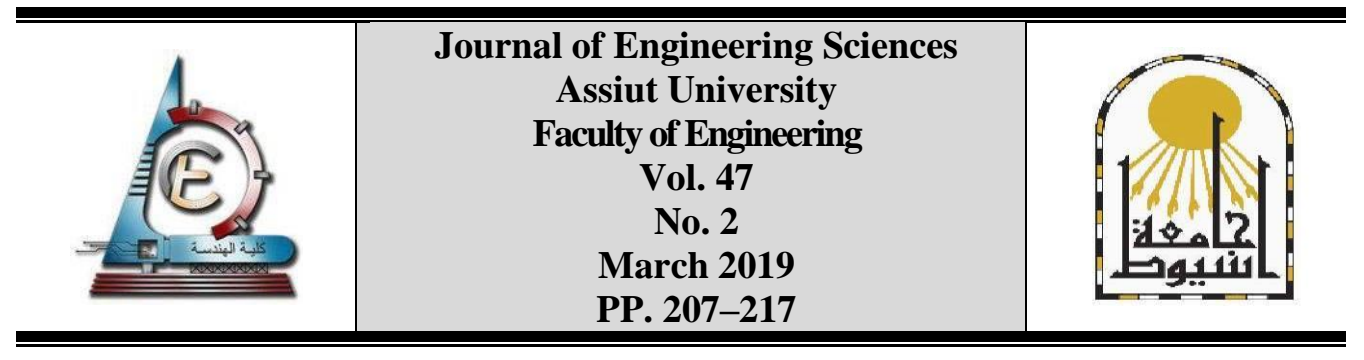

\title{
MULTIPLE INTERFACES IN INFRASTRUCTURE PROJECTS KEY STEPS TO EFFECTIVE AND EFFICIENT MANAGEMENT \\ S. H. ELDAKDOKY
}

Faculty of Engineering, Matria, Helwan University

Received 28 October 2018; Accepted 18 November 2018

\begin{abstract}
In major infrastructure projects, several systems need to work together to achieve a common goal. Getting these systems to work together is no easy feat. Each point where a system is to make contact with another system is an interface. The complexity of such mega projects makes it very important to employ suitable interface management processes right from the beginning of the project. Errors, insufficient planning or overlooked details can result in extensive delays and additional costs. In this study, the interface management process, being employed for the first time in Egyptian infrastructure projects, is introduced. First, the different types of interfaces are identified. Interface documentation including the interface management plan, interface matrix, interface register, interface control form and the interface agreement are explored. Next, the interface process is studied through the three stages of a project lifecycle. And finally, the key steps are developed by integrating the required input and documentation during the interface lifecycle and work stages in a schematic diagram.
\end{abstract}

Keywords: Interface Management process, stakeholder, System Breakdown, Infrastructure projects, Integrated Contract, schematic diagram.

\section{Introduction}

Infrastructure projects is genuinely complex and of multi-disciplines and contracts, in which several interactions are temporarily existing. Such projects involve uncontrolled work conditions of multi- stakeholders, systems, materials, costs, and schedules during a project life cycle. An interface is defined as a common boundary or an interaction point between various organizations, systems, etc. [1]. So as to clearly define interfaces, the project/system needs to be apportioned into manageable parts of satisfactory complexity level [1]; work breakdown is one of the sure-fire ways of managing such projects and can be done based on Technical/operational or geographical aspects either. To ensure work consistently with contract requirements and to resolving integrated issues, Interface Management process (IMs) is implemented for managing all requirements, deliverables, communication, responsibilities and coordination associated with different parties in timely manner [2].

Inefficient IMs in leads to an adverse impact on quality, safety and schedule; in addition to [3]serious issues such as detailed design flaws, work iteration, discrepancies, cost overruns and integration problems during the stage of testing and commissioning [4]. Integrated issues are responsible for about $20 \%$ of total project cost [5]. For instance, 
Betuweroute's freight railway of $160 \mathrm{~km}$ long had experienced significant delay resulting from underestimated interfaces at the preliminary stage of the project.

\subsection{Literature review}

The difficulties of interface management due to the narrow range of the related information distribution were studied by Siao and Lin [6]. The researchers presented a Matrix for construction interfaces that can enable managers and participants of obtaining information required for interface managing. The study developed an interface information management system (CIIM) by combine the proposed matrix with web technology for a construction project. Interface relationships among stakeholders and related information about interface status were included in this matrix as well. The result showed that CIIM was efficiently enhancing the interface management during construction phase.

Design-construction interface issues negatively impact on overall construction project performance i.e. time, quality and cost. Desai et al investigated principal issues of interface management and their effect on construction projects of Surat region. A holistic questionnaire was accomplished based on data collected from field survey, interviews literature and reviews. The results demonstrated that the major issues are lack of communication, coordination and management as well as unprofessional managers. However, teamwork can mitigate these interface issues and improve possibility of project success. Finally, the work recommended use of BIM (Building Information Modeling) to decrease work iteration and design errors [7].

Role of interface management in a construction project was studied by Keerthanaa and Shanmugapriya [4]. The researchers aimed to give an overview of interface management process and steps in a construction project. They were also studied causative reasons for interfacial issues as well as interfaces classification, which are organizational, physical, and contractual interfaces.

Implementing of interface management is commonly varied in account of it is an emerging trend. Shokri, et al investigated the impact of systematic interface management on performance of forty six projects. The results clarified that IM process is mostly correlated with industrial projects of high budget and numerous stakeholders. From performance perspective, projects implementing interface management have fewer cost overruns [8].

\subsection{Problem definition}

Cairo Metro is the Rapid Transit System opened in 1987 as Line1 with a length of $29 \mathrm{~km}$. As of 2014, Cairo Metro network had a total length of $77.9 \mathrm{~km}$ with 61 stations. Currently, the under-construction phase, phase 3 of Line3, has $17.7 \mathrm{~km}$ and 15 stations, in which IMs is applied for the first time in Cairo Metro Project. Applying IMs aims to obviate the discrepancies previously experienced due to the nature of the project, multiple stakeholders and the contract type. The contracting is a design and built contract for six different groups of works as depicted in Fig.1.

Accordingly, a lack of experience together with complexity nature of a project and a multiple integrated contract result in more overlapping activates and inefficient coordination. Therefore, key-steps pertinent to IM process are indeed needed to guide work in such projects. 


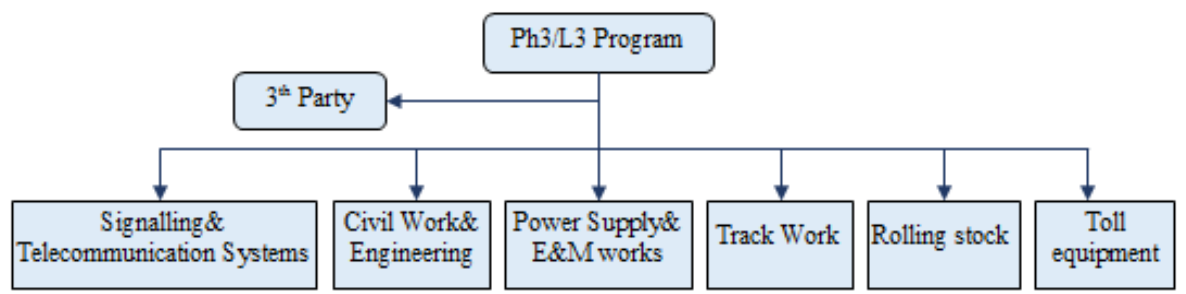

Fig 1. The work's Groups [9]

\subsection{Objective}

This work aims to develop key-steps to implement interface management process and documentation within life cycle of integrated contracts. Thus, a schematic diagram will be developed for managing interface process of infrastructure projects.

\subsection{Method}

To achieve the work objective, a literature review on related works is explored. Second, common IM steps are briefly clarified. Then, the difficulties and benefits of implementing IM process are reviewed, and types of interfaces are explored. Different Interface tools, framework through the life cycle of infrastructure projects are studied. Finally, the work is analyzed and discussed to establish key-steps to manage interface process.

\section{Interface management steps}

Interface Management is a methodical approach for identifying, documenting, and dealing with interfaces during a project [10]. IM process generally consists of five typical steps as follows [4] [1] [10]:

1) Identification of interfaces which runs parallel to the design process, and focuses on external and inter-interfaces. Potential interfaces are usually identified using design documents and contractors' experiences.

2) Documentation which includes interface related information, interface documents, time frame, level of interface etc. It is worth mentioning that this step is an ongoing process through entire interface management system.

3) Interface Transferring, issuance of package, in which identified interface points and information are transferring between the stakeholders. The implementation is counting on verification and validation $(\mathrm{V} \& \mathrm{~V})$.

4) Verification and Validation $(V \& V)$ are to check the fulfillment of a project's requirements; this step occurs in inspection, testing and acceptance phases and is associated to the interface certification.

5) Certification step which includes agreement and formal sign-off process of interface requirements, design, implantation and acceptance. Interface is closed as soon as stakeholders confirmed suitability of communicated information and deliverables.

\section{Difficulties and benefits to implement IM process}

It is important to distinguish between interfaces prior to explore the difficulties and benefits of implementing the IMs. Interfaces are generally of three types; extra, inter, and intra interfaces:

1) Third party/ Project external interface is done with third party such as authority public utilities; this type of interfaces is usually managed by the concerned contractor. 
2) Inter-contract interface is carried out between two or more different contractors, such as an interface point regarding spatial provisions between a track work and civil work contractors.

3) Intra-contract interface is internally required within one contract, such as interfaces between structural and architectural elements.

\subsection{Difficulties to implement IM process}

IM failure results from environmental and/or Know-how reasons. The environmental reasons not only include weather and geological conditions, but also legislations, act-ofgod, and contract commitments. Inconsistency and/or ambiguity between contract documents, and continuous changes to the Basic documents cause interface issues. Moreover, unfamiliarity of project's parties with audit of local authority and laws impose delays on interfaces [10].

Know-how reasons get back to various problems related to managing, coordination and experience. It results in ineffectual decision-making, confusion of scope and responsibilities between stakeholders, miscommunication, poor coordination and interfaces.

\subsection{The benefits to implement IM process}

Many benefits result from implementing the IM process as follows [4] [11]:-

- Simplify a complexity of project, and resolve interface matters to a satisfaction of Employer.

- Enhance project's planning due to earlier removal of interfacial matters.

- Avoid the Uncertainties in a work because of integrated work flow, and upgrading coordination and Communication between project parties.

- Apportioned a project/system into manageable parts which can be clearly identified and tracked in order to improve project's budget and schedule.

\section{Interfaces tools}

Interface parties normally need several information to effectively handle interfaces. Track and control of interfaces are essential to monitor overall progress, to resolve integration issues, and to verify solutions during lifecycle of a project. Interface inputs and outcomes generated and associated with interface activities are in the following format [1] [12].

\subsection{Interface management plan (IMP)}

Interface Management Plan (IMP) outlines all procedures to achieve interface objectives. It generally defines type of interfaces, relationships and responsibilities of all concerned parties, information to be exchanged of all phases, process of interface tracking and verification, management document, tools and methods, inputs, and deliverables [1]. IMP includes also management of interface changes and risk issue associated with interfaces [13].

\subsection{Interface matrix (IMx)}

Interface matrix clarifies a dependent nature of interfaces. An IMx is prepared to deliver a clear view for elements have interfaces with each other. Inter\& external contract interfaces are included as well. Figure 2 shows a sample of IMx in which a list of interfaces, limit of responsibility between concerned contractors, interface status as well as a provider and a requester of interface data are mentioned. 
S. H. Eldakdoky, Multiple Interfaces In Infrastructure Projects Key Steps To Effective ..............

A simple $\mathrm{N}$-squared diagram is in a shape of matrix and can be used at early stage of a project when several details are not known yet. As depicted in Fig. 3, preliminary interfaces are found between three disciplines, where no common system for gathering and controlling interfaces [12]. A higher detail level of $\mathrm{N}^{2}$-diagram is not recommended, where critical information might be missed and interfaces are lost accordingly.

\begin{tabular}{|c|c|c|c|c|c|c|c|c|c|}
\hline $\begin{array}{l}\stackrel{8}{0} \\
\dot{0} \\
\underline{0}\end{array}$ & 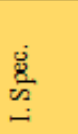 & $\underline{\underline{\Xi}}$ & .气 & 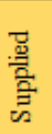 & $\begin{array}{l}\text { 总 } \\
\text { 憘 } \\
\text { 至 }\end{array}$ & 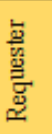 & $\frac{b}{3}$ & 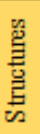 & 墨 \\
\hline $\begin{array}{l}\mathrm{INT} \\
\text { ISG } \\
001\end{array}$ & 2.2 .1 .1 & Floor losds in structures & $\begin{array}{l}\text { C03 shall provide to } \\
\text { C01 the floor loads } \\
\text { requirements }\end{array}$ & $\mathrm{C} 01$ & $\mathrm{CO3}$ & $\mathrm{CO1}$ & $\mathrm{CO3}$ & 15 & open \\
\hline $\begin{array}{l}\text { INT } \\
\text { ISG } \\
002\end{array}$ & 2.2 .1 .3 & $\begin{array}{l}\text { Equipment installation in } \\
\text { smex structures } \\
\text { (equipment location \& } \\
\text { delivery routes) }\end{array}$ & $\begin{array}{l}\text { C01 shall coordinate } \\
\text { with C } 05 \text { to settle all the } \\
\text { equipment location and } \\
\text { delivery routes. }\end{array}$ & $\mathrm{CO1}$ & $\cos$ & $\mathrm{CO1}$ & $\cos$ & 48 & $\begin{array}{l}\text { In } \\
\text { progress }\end{array}$ \\
\hline
\end{tabular}

Fig. 2. Sample of IMx [9]

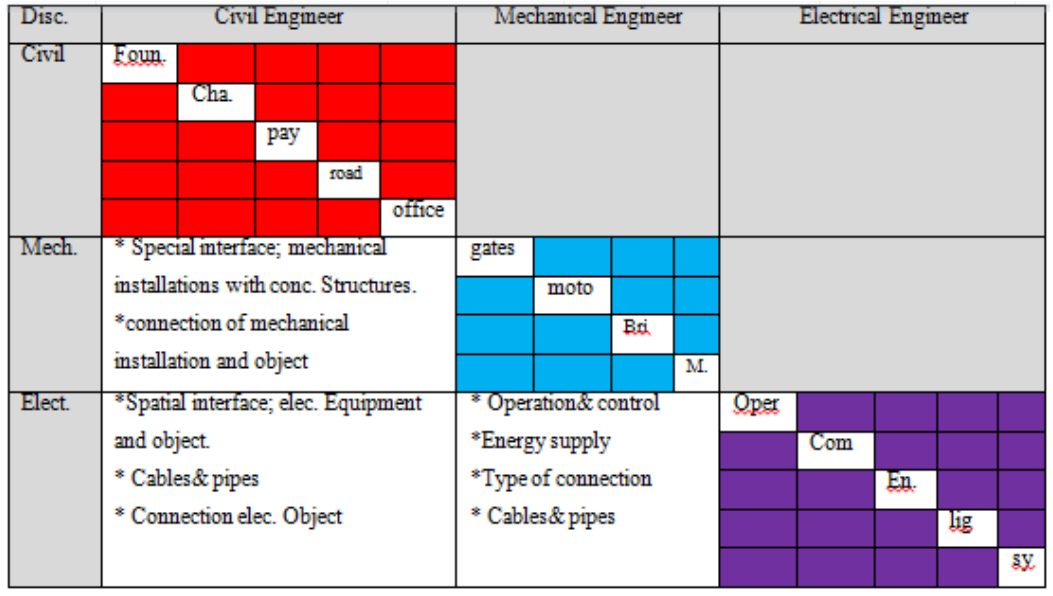

Fig. 3. Example of $\mathrm{N}^{2}$-diagram of four contractors [12]

\subsection{Interface register (IR)}

All interfaces are to be stored in interface register (IR) in which they are listed using ID-number similar to ID indicated in IMx. Identified points of interfaces are kept in the Interface Register. As shown in Fig.4, an IR is in a form of extracted spreadsheet including all related information to follow interfaces and keeping everyone up to date

\begin{tabular}{|l|l|l|l|l|l|l|l|l|l|l|}
\hline \multicolumn{2}{|l|}{ Interface register } \\
\hline ID & Title & Descr & Type & Status & Object ID & Object & $\begin{array}{l}\text { Concerned } \\
\text { Contractor }\end{array}$ & Req.ID & Pesp. & Risk \\
\hline & & & & & & & & & & \\
\hline
\end{tabular}

Fig 4. Sample of an Interface register [12]

\subsection{Interface control form (ICF)}

Interface control form (ICF) is a structured report to collect, document, describe, transmit and implement interface related information and requirements in points. ICF, as shown in Fig.5, is as precise and concise as possible without reiterating any information. Characteristics and process leading to an interface solution and verification plan are to be 
included. Each interface has one ICF which could come in several forms, and interface is to be closed in IR after completion of an interface [14].

\section{Interface Control Form}

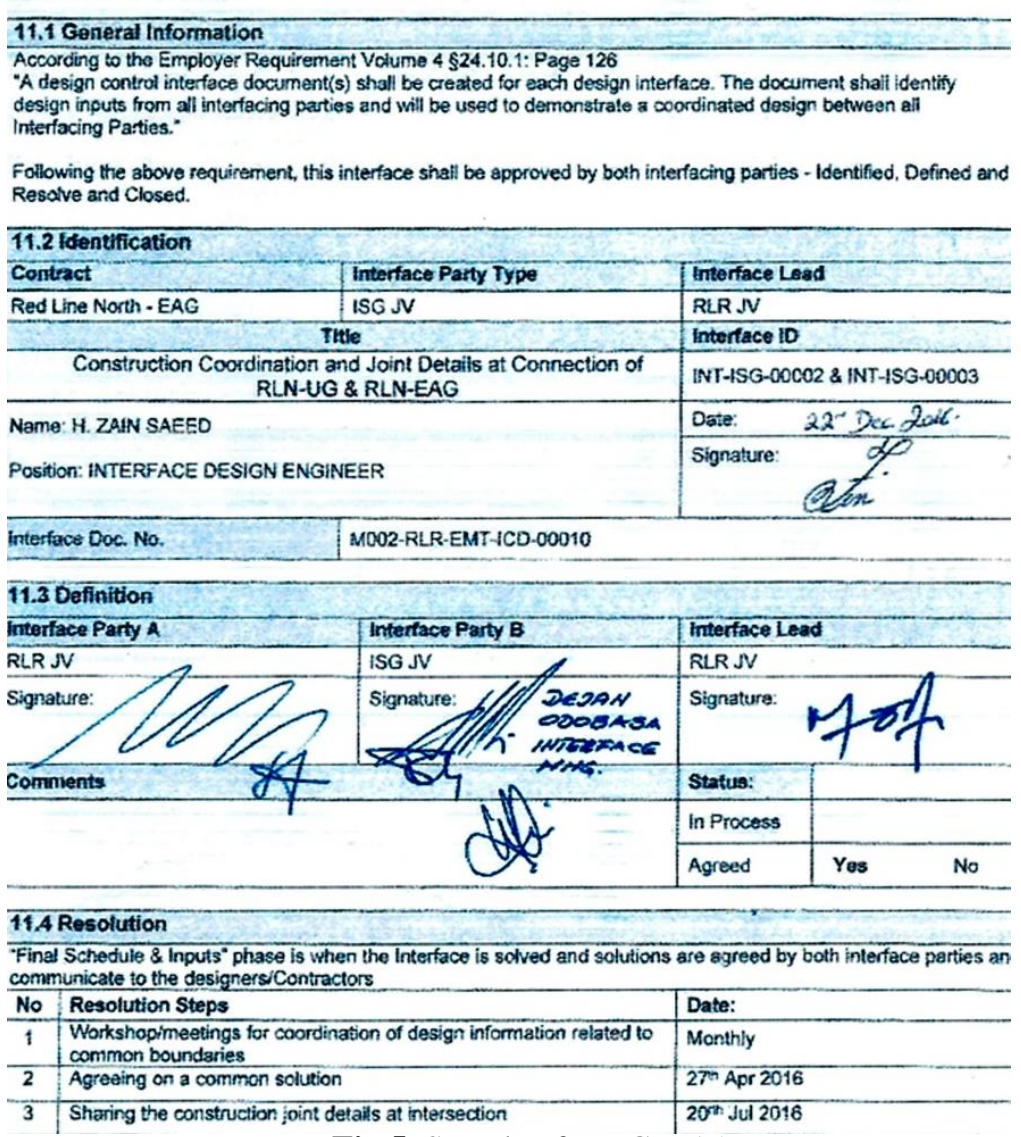

Fig 5. Sample of an ICF [15]

\subsection{Interface agreements (IAs)}

Interface agreement is a formal agreement used to regulate information exchange and deliverables between concerned parties. It is usually attached to ICF and used only for external and inter-disciplinary interfaces. Generally, a requester writes an IA and requests for specific information, within an allocated time frame, from the other party who signs this document as shown in Fig.6. The aim of his form is to control and monitor interfaces points through agreements between concerned parties.

\begin{tabular}{|l|l|l|l|l|l|l|c|}
\hline \multicolumn{1}{|l|}{ Interface Agreement register } \\
\hline Agreement ID & Requester & Responder & I.ID & Object ID & Object & Due Date & Status \\
\hline & & & & & & & $\begin{array}{c}\text { Open, In progress, } \\
\text { Verification, Closed }\end{array}$ \\
\hline
\end{tabular}

Fig. 6. Sample of IA [12] 


\section{Framework and life cycle}

Life cycle of an Interface management process is categorized into three stages. Each stage includes three subordinate steps, as depicted in Fig. 7.

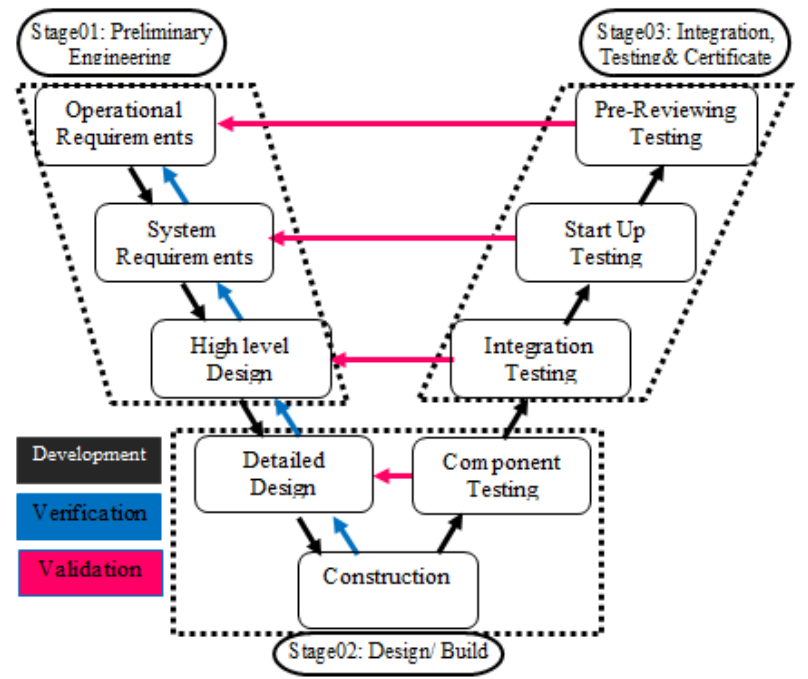

Fig.7. Life-Cycle of Interface Management process [1]

\subsection{The criteria at stage one}

IMs preliminary requirements and inputs need to be determined in this stage, which include Base Design, interface technical specifications, operational and maintenance specifications, requirements of reliability, availability, maintainability and safety (RAMS), and requirements of regulatory system. The main objective of this stage should outline IM preliminary requirements, contractors' scope and responsibility.

\subsection{The criteria at stage two}

All contractors at this stage are required to upgrade and implement a particular IM process to ascertain that specified interfaces are implemented holistically and correctly.

The inputs of Detailed Design step are IM requirements, interfaces list, work scope as well as General and particular provisions. While the Outputs and Deliverables are IMP, IMx, IR, ICF and IA. They should show detailed design is in compliance with contract requirements.

The inputs of the Construction and Inspections step are the inputs into and output from the Detailed Design step, and ready for construction (RFC) documents. While the outputs and deliverables in this step are implementation, inspection and verified the deliverables.

The compliance of IMs is demonstrated in Testing and Acceptance step through a holistic inspections and tests. The inputs required are the Inputs, Output and deliverables from the final design and construction.

Outputs and Deliverables are Tested and accepted interfaces through

- Revised, verified, and certified IAs and ICFs

- Conformance Construction certificate (CCC) in accordance with the Safety and Security MP. 


\subsection{The criteria at stage three}

Finally, the system is to be integrated, tested, and certified under the supervision of the Organization. The inputs required to this stage are involving:

- Outputs and deliverables from completed contracts included; final IAs, ICFs, V\&V submittals, reports of Interface test and acceptance and conformance Construction certificates.

- Outputs and deliverables from Program planning included critical interfaces List.

IM Deliverables are: final testing and commissioning plan, procedures and test results and Certification of Compliance System Safety Program Plan.

\section{Discussion}

Commonly, an IM process follows five steps during its life cycle. Meanwhile, a development of any infrastructure project goes through three stages, in which many stakeholders are concerned. Thus, there is an inevitability to regulate which party will adapt and adjust his work to the others. Hence, following systematic steps for IM to minimize integration issues, provided that accurate information is identified based on contract documents and realistic needs of all parties.

Work scope of each party has to be obvious before identifying the interfaces can be effective. To sufficiently allocate project activities to concerned parties, systems breakdown and coupling all subsystems to each other are required at Stage 01, in which all information required for Stage 03 verification is presented.

Moving on to the Design\& Build Stage, Stage 02, interfacing parties adhere to information from Stage 01, where an IMP has to be designed to map Coordination principles between stakeholders. Managing interfaces requires not only precise identification and effective communication, but also follow up, monitoring and verification.

Tracking and Monitoring are carried out during the whole procedure. Which ensures compliance with requirements specified in Stage 01, and correction of flaws and conflicts? While validation is carried out during Stage 03, Integration, Testing\& Certificate Stage, after which the interface can be closed.

The IMP, IMx, IR, IAs, and ICFs are the main tools used for Interface documentation. By using these tools, all stakeholders will have clear vision of what is supposed to happen, when and with whom information is to be exchanged and communicated. The interface progresses as well as interface closing are to be reported periodically to the Client.

In here, six systematic key Steps of IM process can be adopted, as depicted in Fig.8. Step one is entirely included in the Preliminary Engineering Stage. Steps 02-05 are included in Design\& Build Stage. Here, interface tools, meetings, notifications and reports can be used for communication, information exchange and resolving conflicts. Step 05 is included at Integration, Testing\& Certificate Stage in which V\&V of submittals are done. Final testing and commissioning plan, procedures, test results and Certification of Compliance of system are the final output based on which the Interfaces can be closed.

\section{Conclusion}

Six systematic key Steps can be adopted to ensure success implementing of IM process. First, managerial and technical aspects need to be applied prior to IM process begin, which 
include; i) Scope of work for stakeholders; ii) Break down a project into manageable parts; iii) Well-structured IM process and iv) Interface tools.

Next, an IM process has to start with an IMP in which a structure of a process and tools are to be established. Following IMP, effectual interface tools are necessity to enhance IM process by achieving consistent information exchange and documentation.

Generally, all interface points are mostly identified based on Contract documents and contractors' experience. However, subsystems and interface meetings are necessary to identify physical and functional interfaces. IMx and $\mathrm{N}^{2}$-chart are effectual tools can be used to identify and list all possible interfaces. Using only $\mathrm{N}^{2}$-chart will not be effective, whereby critical interfaces will often be lost.

Once interfaces are identified, it is essential to be listed in IR for following up and tracking, so IR needs to be periodically updated. Communications and information exchange are to be carried out through meetings and formal ICF\& IAs. Use only IAs as a formal way of information exchange is not enough tool to resolve interfaces. Moreover, interfaces control is a very important step to follow up overall progress, find out any shortage, verify interface resolutions, and resolve any issues during project's life cycle. That step is usually overlooked and replaced by monitoring the status.

The above mentioned key-steps improve IM process through better coordination, active communication and distribution of exchanged information within concerned parties. They also help in error detecting, identifying and resolving of conflicts, and verifying of design.

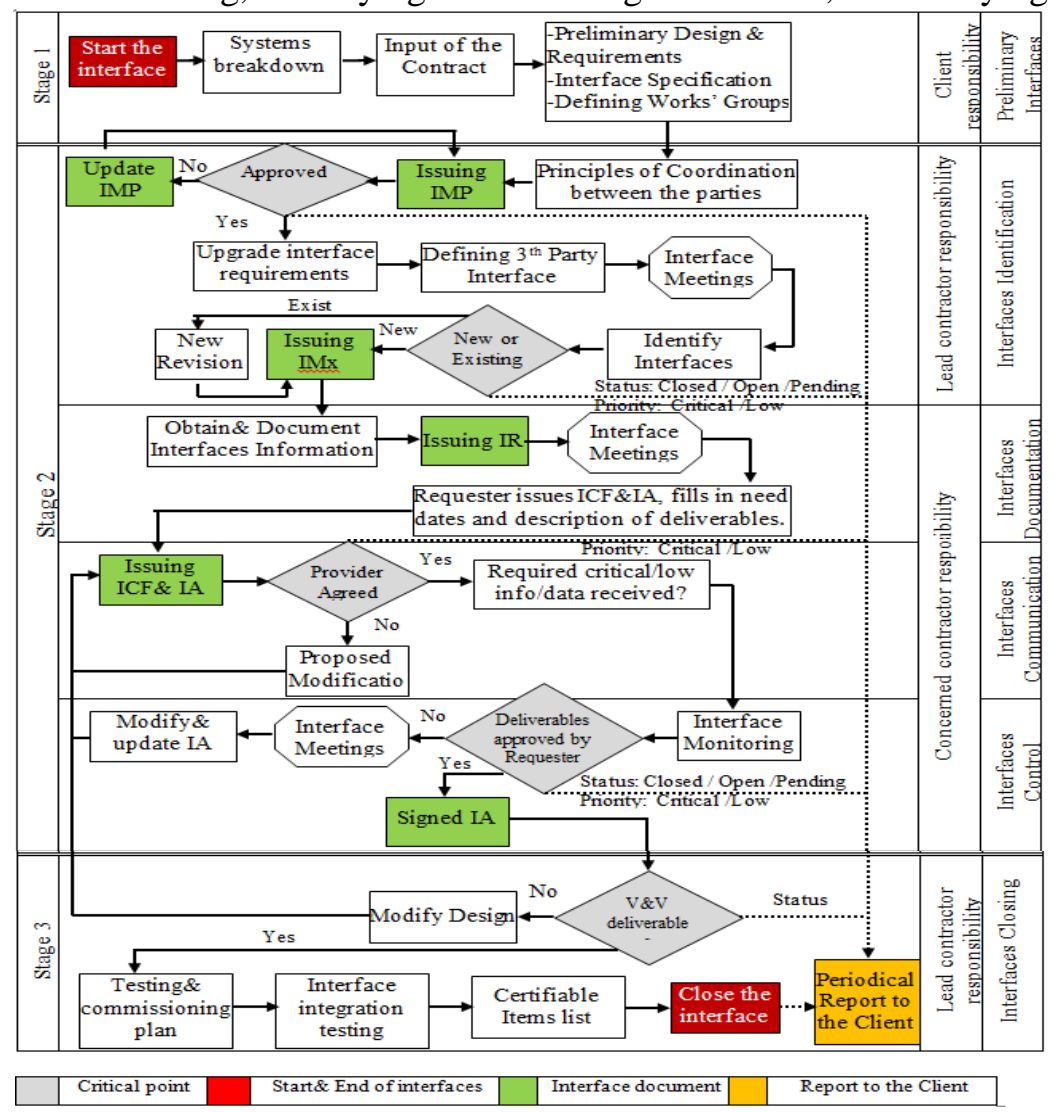

Fig. 8. Configuration Key-points of IM Process 


\section{REFERENCES}

[1] Hoehne, O., Banks, B., Chirco, J., and Felker, B, "Technical Memorandum- Interface Management Plan", California High-Speed Train Rail Authority, USA, 2013.

[2] Daniels, et al, "Interface Management On Mega Projects: A Case Study", 50 ${ }^{\text {th }}$ ASC Annual International Conference Proceedings, USA, 2014.

[3] Shokri, S., "Interface Management Model for Mega Capital Projects,", Construction Research Congress, ASCE, 2012.

[4] Keerthanaa, K. and Shanmugapriya, S., "Role of Interface Management in Construction Industry", International Research Journal of Engineering and Technology (IRJET), vol. 4, no. (2), p. 1217-1220, 2017.

[5] Nooteboom,U., "Interface Management Improves On-time, On-Budget Delivery of Megaprojects", Petroleum Engineers Journal, vol. 26, no. 08, 2004.

[6] Siao, F.C., and lin, Y.C., "The Development of Construction Interface InformationManagement System", $28^{\text {th }}$ International Symposium on Automation and Robotics in Construction, Korea, 2011.

[7] Desai, J., Pathak, V., and Yadav, N., "Evaluation of Design-Construction Interface Problems in Building Construction Projects," International Journal for Research in Applied Science \& Engineering Technology (IJRASET), vol. 6, no. 4, pp. 242-247, 2018.

[8] Shokri,S., "Current Status of Interface Management in Construction: Drivers and Effects of Systematic Interface Management," Journal of Construction Engineering and Management, vol. 142, no. 2, 2015.

[9] Greater Cairo Metro, Contract No.78/M-Line3/Phase 3, National Authority for Tunnels, 2017.

[10] Ahn, S., Shokri, S., Lee, S., Haas, C., and Haas, R., "Motivation For Interface Management In Construction: A Project Complexity Perspective", $5^{\text {th }}$ International/11th Construction Specialty Conference, Columbia, 2015.

[11] Staats, S., "Interface Management in Multidisciplinary Infrastructure Project Development", Delft University of Technology, Nederlands, March, 2014.

[12] Liu,T. "Conflicting Objectives in Interfaces of Construction Project", The Norwegian University of Science and Technology, Faculty of Social Sciences and Technology Management, 2014.

[13] Coyn, D.and Lazzaini, A., "Interface Control Document: Beam T[be (BT) - Civil Construction", California Institute of Technolog\& Massachusetts Institute of Technology, USA, 1995.

[14] Qatar Red Line North elevated and at grade, contract No. RTC/081/2013, vol.5, Appendex B, 2016. 


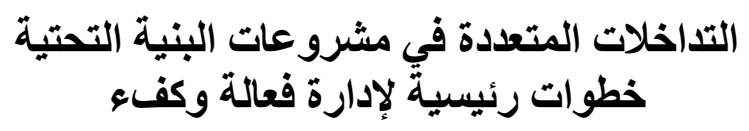

الملخص العربى:

أن أهمية عملية إدارة التداخلات خلال دورة حياة مشرو عات البنية التحتية ترجع إلى الطبيعه المعقدة لهذه التهاء

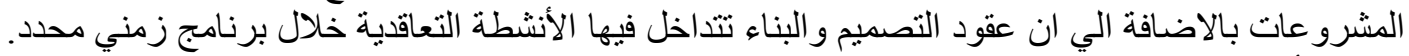

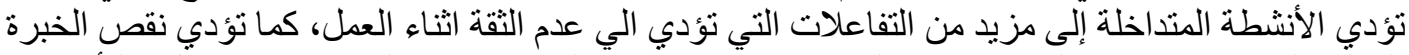

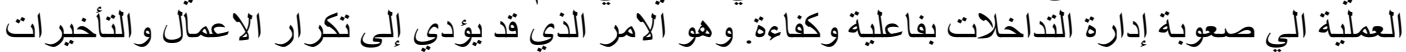

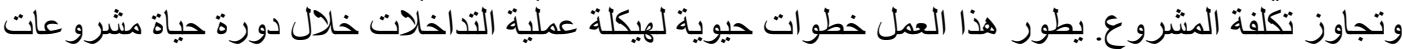

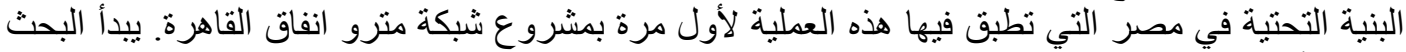

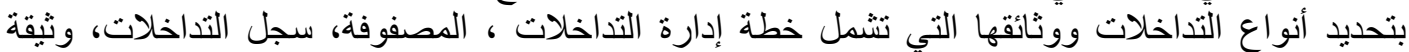

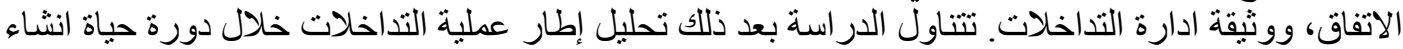

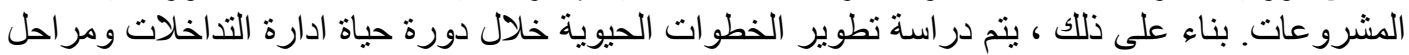

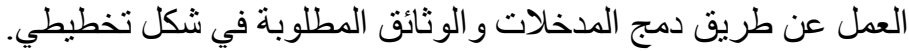

